\title{
INFLUÊNCIA DE NITROGÊNIO AMONIACAL E VAZÃO DE AR NO PROCESSO DE NITRIFICAÇÃO, ETAPA DE TRATAMENTO DE EFLUENTE DE ABATEDOURO DE PEIXE ${ }^{1}$
}

\author{
LIDIANA ANDRADE ${ }^{2}$, ANA C. B. KUMMER ${ }^{3}$, AJADIR FAZOLO ${ }^{4}$, \\ SIMONE DASMACENO ${ }^{5}$, SALAH D. M. HASAN ${ }^{6}$
}

\begin{abstract}
RESUMO: O efluente proveniente de abatedouro de peixes possui alto teor de nitrogênio, um dos principais causadores de eutrofização nos corpos d'água. Sua remoção pode ser feita em duas etapas separadas: nitrificação e desnitrificação. Este experimento teve como objetivo testar a influência da vazão de ar (valores de 1 a $3 \mathrm{~L} \mathrm{~min}^{-1}$ ) e a concentração de nitrogênio amoniacal (de 40 a $100 \mathrm{mg} \mathrm{L}^{-1}$ ) no processo de nitrificação. Foi utilizado um reator em batelada sequencial com biomassa imobilizada, com volume útil de 2,5 L, operado conforme delineamento composto central rotacional, em que as variáveis-resposta analisadas foram percentagem de conversão de nitrogênio amoniacal a nitrato e percentagem de acúmulo de nitrito. Os resultados mostraram, com intervalo de confiança de $95 \%$, que o aumento dos dois fatores diminuiu significativamente a percentagem de conversão de nitrogênio amoniacal a nitrato. Já a percentagem de acúmulo de nitrito aumentou significativamente quando houve aumento da concentração de nitrogênio amoniacal, não sendo influenciada significativamente pela vazão de ar. Durante o experimento, a melhor condição de operação encontrada para o equilíbrio das reações foi com concentração de nitrogênio amoniacal de $70 \mathrm{mg} \mathrm{L}^{-1}$ e com vazão de ar de $2 \mathrm{~L} \mathrm{~min}^{-1}$.
\end{abstract}

PALAVRAS-CHAVE: efluente anaeróbio, remoção de nitrogênio, nitrificação.

\section{AMMONIA NITROGEN AND AIR FLOW INFLUENCE ON NITRIFICATION PROCESS, PART OF THE TREATMENT FOR FISH SLAUGHTERHOUSE EFLUENT}

\begin{abstract}
The fish slaughterhouse effluent presents high levels of nitrogen, one of the major causes of eutrophication in water bodies. Nitrogen removal can be accomplished in two separate stages: Nitrification and Denitrification. This experiment aimed to test the influence of air flow (values between 1 and $3 \mathrm{~L} \mathrm{~min}^{-1}$ ) and ammonia nitrogen concentration (between 40 and $100 \mathrm{mg} \mathrm{L}^{-1}$ ) in the nitrification process. A $2.5 \mathrm{~L}$ volume sequencing batch reactor with immobilized biomass was operated as central rotational composed design, where the evaluated results were conversion of ammonia nitrogen to nitrate in percentage and nitrite accumulation in percentage. The results with confidence interval of $95 \%$ showed that the increase of both variables resulted in the significant reduction of the percentage of nitrogen conversion to nitrate. The nitrite accumulation percentage significantly increased with the ammonia nitrogen increase, although it was not observed significant influence of air flow. During the experiment the best condition found for the equilibrium of the reactions was $70 \mathrm{mg} \mathrm{L}^{-1}$ of ammonia nitrogen and air flow of $2 \mathrm{~L} \mathrm{~min}^{-1}$.
\end{abstract}

KEYWORDS: fish slaughterhouse, anaerobic effluent, nitrogen removal, nitrification.

\footnotetext{
${ }^{1}$ Extraído de dissertação de Mestrado do primeiro autor.

${ }^{2}$ Bióloga, Mestre em Engenharia Agrícola, UNIOESTE, Cascavel - PR, lidi_ana@ hotmail.com

${ }^{3}$ Eng $^{\mathbf{o}}$ Agrícola, Mestre em Engenharia Agrícola, UNIOESTE, Cascavel - PR.

${ }^{4}$ Prof. Adjunto, Universidade Tecnológica Federal do Paraná, UTFPR, Londrina - PR.

${ }^{5}$ Prof. Adjunto, Centro de Ciências Exatas e Tecnológicas, UNIOESTE, Cascavel - PR.

${ }^{6}$ Prof. Adjunto, Centro de Engenharia e Ciências Exatas, UNIOESTE, Toledo - PR.

Recebido pelo Conselho Editorial em: 9-9-2008

Aprovado pelo Conselho Editorial em: 12-12-2009
} 


\section{INTRODUÇÃO}

Desde 1990, o cenário econômico brasileiro conta com o peso da aquicultura comercial, que, na época, produzia $25.000 \mathrm{t} \mathrm{ano}^{-1}$ (BRASIL, 2007). Em 2006, PINHEIRO (2006) escreveu que a produção nacional de filés de tilápia havia aumentado para $70.000 \mathrm{t} \mathrm{ano}^{-1}$, e que a região Sul era responsável por $70 \%$ da produção nacional.

Os efluentes das indústrias de abate de peixes são compostos pela combinação da água com sangue e pedaços de carne, mistura decorrente do processo de filetagem. A água residuária desse processo agrega características de elevada concentração de matéria orgânica e diversos nutrientes, dentre os quais se destaca o nitrogênio por seu efeito no meio ambiente relacionado à eutrofização (ISOLDI \& KOETZ, 2004).

A resolução 357/2005 do CONAMA (BRASIL, 2005), que classifica os corpos de água, apresenta padrões de qualidade de água para os corpos hídricos e padrões de lançamento para os efluentes. Nessa resolução, os lançamentos não podem extrapolar o limite de $20,0 \mathrm{mg} \mathrm{L}^{-1}$ de nitrogênio amoniacal.

Segundo KAWANO \& HANDA (2002), nos tratamentos biológicos de águas residuárias, procura-se repetir, em ambiente restrito e em curto espaço de tempo, a autodepuração, mesmo processo que se verifica ao longo do curso de um rio ou na área de um lago. De acordo com FERREIRA (2000), nesses tratamentos, a remoção de nitrogênio pode ser realizada por meio da nitrificação, seguida de desnitrificação. A nitrificação é realizada por bactérias nitrificantes que existem naturalmente em sistemas onde há condições aeróbias e presença de nitrogênio amoniacal.

Segundo TORRES et al. (1997), na nitrificação, a amônia é oxidada a nitrito (processo denominado nitritação), principalmente pelas bactérias dos gêneros Nitrosomonas e Nitrosococcus, conforme eq. (1). Os nitritos, por sua vez, são oxidados a nitratos (processo denominado nitratação) pelas bactérias Nitrobacter, Nitrocystis e Nitrospina, conforme eq. (2):

$$
\begin{aligned}
& 2 \mathrm{NH}^{4+}+3 \mathrm{O}_{2} \stackrel{\text { Nitritação }}{\longrightarrow} 2 \mathrm{NO}^{2-}+2 \mathrm{H}_{2} \mathrm{O}+4 \mathrm{H}^{+}+\text {novas células + energia } \\
& 2 \mathrm{NO}^{2-}+\mathrm{O}_{2} \stackrel{\text { Nitratação }}{\longrightarrow} 2 \mathrm{NO}^{3-}+\text { novas células }+ \text { energia }
\end{aligned}
$$

Esse processo precisa ocorrer sob condições apropriadas, caso contrário, os próprios produtos do metabolismo bacteriano podem causar toxidez no meio, deixando-o nocivo para as bactérias (FERREIRA, 2000). Segundo ABREU (1994), a concentração de amônia ionizada de 10 a $150 \mathrm{mg} \mathrm{L}^{-1}$ é inibitória para as Nitrosomonas sp.. Já as Nitrobacter $s p$. sofrem inibição por amônia em valores de 0,1 a $1,0 \mathrm{mg} \mathrm{L}^{-1}$.

De acordo com VADIVELU (2007), o mecanismo responsável pelo efeito inibitório da amônia livre na respiração das Nitrobacter sp. não é claro. O efeito pode ser devido à ação direta da amônia sobre a enzima nitrite oxidoreductase ou sobre alguma enzima envolvida no transporte de elétrons da cadeia respiratória. Independentemente dos detalhes dos mecanismos envolvidos nesse processo, os autores afirmaram que a amônia livre inibe a produção catabólica de energia pelas Nitrobacter sp., e a redução na atividade respiratória, em quaisquer de seus níveis, inibe o crescimento bacteriano.

Segundo FERREIRA (2000), a concentração de oxigênio dissolvido também tem influência direta sobre a taxa de nitrificação. Taxas ótimas podem ser obtidas com níveis de OD, expresso em $\mathrm{O}^{2}$, da ordem de 4,0 $\mathrm{mg} \mathrm{L}^{-1}$, desde que exista população de bactérias nitrificantes bem adaptada.

De acordo com SURAMPALLI et al. (1997), a velocidade máxima de nitrificação ocorre em concentrações de OD maiores que $2 \mathrm{mg} \mathrm{L}^{-1}$. Caso a concentração seja menor que $0,5 \mathrm{mg} \mathrm{L}^{-1}$, a velocidade de nitrificação reduz drasticamente e pode ser totalmente interrompida.

Este estudo teve por objetivo testar o comportamento do processo de nitrificação em diferentes combinações de concentração de nitrogênio amoniacal e vazão de ar. 


\section{MATERIAL E MÉTODOS}

O efluente utilizado no experimento foi coletado na saída da lagoa anaeróbia de uma empresa de abate de peixes, localizada no município de Toledo - PR, com média de abate de $8 \mathrm{t} \mathrm{dia}^{-1} \mathrm{e}$ consumo de 6 a $8 \mathrm{~L}$ de água por quilo de tilápia abatida, com geração de $56.000 \mathrm{~L}$ de efluente por dia. A caracterização do efluente em laboratório mostrou valores de NTK $=85 \mathrm{mg} \mathrm{L}^{-1}$; nitrogênio amoniacal $=80 \mathrm{mg} \mathrm{L}^{-1} ; \mathrm{DQO}=330 \mathrm{mg} \mathrm{L}^{-1}$; nitrito = não detectado; nitrato = não detectado; alcalinidade $=400 \mathrm{mg} \mathrm{L}^{-1}$, e $\mathrm{pH}=8$.

Este experimento foi realizado no laboratório de Saneamento Ambiental da Universidade Estadual do Oeste do Paraná, Câmpus Cascavel, utilizando-se de um reator aeróbio construído de PVC (Policloreto de vinila), com diâmetro de $150 \mathrm{~mm}$ e altura de $200 \mathrm{~mm}$, resultando em volume útil de 2,5 L.

Foram realizadas bateladas com ciclo de duração de 24 horas, nas quais foram testados o fator vazão de ar (Qar) e a concentração inicial de nitrogênio amoniacal. As vazões de ar utilizadas foram determinadas a partir de experimentos realizados por ZENATTI (2007), que testou vazões de ar de 6 e $3 \mathrm{~L} \mathrm{~min}^{-1}$ e não foram verificadas diferenças significativas no desempenho do processo. Assim, pensando no menor gasto de energia para a aeração, neste estudo, foram estipuladas vazões de ar na faixa de 3 a $1 \mathrm{~L} \mathrm{~min}^{-1}$. Para a variável concentração inicial de nitrogênio amoniacal, foi determinado o nível mais alto de concentração de entrada do reator como sendo de $100 \mathrm{mg} \mathrm{L}^{-1}$ de nitrogênio amoniacal, e o nível mais baixo, de $40 \mathrm{mg} \mathrm{L}^{-1}$.

A aeração do reator foi feita com o auxílio de aeradores de aquário (Big-Air - modelo A-420) acoplados a fluxômetro; o ar era encaminhado até o reator por meio de mangueira de silicone com pedra porosa na extremidade para diminuir o tamanho das bolhas de aeração. As concentrações de nitrogênio amoniacal no efluente foram controladas por meio de diluições ou adição de cloreto de amônia.

Foi utilizado o Delineamento Composto Central Rotacional (DCCR), conforme Tabela 1, para avaliar a influência dos fatores em superfícies de resposta, de acordo com metodologia apresentada por BARROS NETO et al. (1996). Utilizou-se do planejamento composto por dois fatores em níveis " +1 e -1 " combinados, resultando em quatro ensaios; três pontos centrais " 0 ", resultando em três ensaios; e dois pontos axiais " $+1,414$ e $-1,414$ " combinados com o ponto central " 0 ", resultando em mais quatro ensaios, totalizando, para esse delineamento, 11 ensaios. Os testes estatísticos foram realizados pelo programa estatístico Statistic 7.0.

TABELA 1. Valores do delineamento experimental e concentrações reais. Values of the experimental design and real concentrations.

\begin{tabular}{lcrrrc}
\hline Delineamento & $-1,414$ & -1 & 0 & +1 & $+1,414$ \\
\hline Qar $\left(\mathrm{L} \mathrm{min}^{-1}\right)$ & 1 & 1,3 & 2 & 2,7 & 3 \\
N Amoniacal $\left(\mathrm{mgN} \mathrm{L}^{-1}\right)$ & 40 & 48,8 & 70 & 91,2 & 100 \\
\hline
\end{tabular}

Foram realizados os ensaios de forma aleatória e casualizada, sendo quantificados os seguintes parâmetros: Nitrogênio Amoniacal, Nitrito e Nitrato para o monitoramento do processo de nitrificação; e a relação alcalinidade/nitrogênio consumido, relação $\mathrm{C} / \mathrm{N}$ e $\mathrm{pH}$ para acompanhamento da homogeneidade das condições. Todas as análises foram feitas conforme metodologia Standard Methods $20^{\text {th }}$ Ed (APHA, 1998).

\section{RESULTADOS E DISCUSSÃO}

Durante o experimento, foram monitoradas as condições químicas e, em todos os ensaios, foi observado o mesmo comportamento: $\mathrm{pH}$ de início das bateladas por volta de 8,5 e de saída da batelada entre 7,5 e 8; relação $\mathrm{C} / \mathrm{N}$ abaixo de 3 (valor médio em 2,8), e relação 
alcalinidade/nitrogênio consumido entre 6,5 e 7 . Os resultados obtidos de nitrato e nitrito estão apresentados na Tabela 2.

TABELA 2. Combinações do DCCR e resultados de nitrato e nitrito. DCCR combination and results of nitrate and nitrite.

\begin{tabular}{cccc}
\hline Concentração de N Amoniacal & Vazão de Ar & Conversão a Nitrato (\%) & Acúmulo de Nitrito (\%) \\
\hline-1 & -1 & 57,3 & 8,2 \\
1 & -1 & 72,0 & 16,0 \\
-1 & 1 & 53,4 & 8,2 \\
1 & 1 & 68,9 & 15,0 \\
0 & 0 & 85,8 & 12,6 \\
0 & 0 & 85,0 & 18,0 \\
0 & 0 & 86,0 & 18,0 \\
1,414 & 0 & 58,0 & 35,7 \\
$-1,414$ & 0 & 60,5 & 5,0 \\
0 & $-1,414$ & 80,3 & 15,0 \\
0 & 1,414 & 65,0 & 9,0 \\
\hline
\end{tabular}

A partir dos dados acima, foram geradas, com o auxílio do programa Statistic 7.0, as Tabelas 3 e 4 com os efeitos para cada variável-resposta.

TABELA 3. Tabela de efeitos para a variável-resposta percentagem de conversão a nitrato. Effects of the response: percentage of convertion to nitrate.

\begin{tabular}{lrccccc}
\hline & Efeito & $\begin{array}{c}\text { Erro-Padrão do } \\
\text { Efeito }\end{array}$ & $\begin{array}{c}\text { t de Student } \\
(5 \%)\end{array}$ & p-valor & $\begin{array}{c}\text { Coeficiente } \\
\text { do Modelo }\end{array}$ & $\begin{array}{c}\text { Erro do } \\
\text { Coeficiente }\end{array}$ \\
\hline Média & 85,6197 & 3,539775 & 24,18788 & 0,000002 & 85,6197 & 3,539775 \\
$(1) Q$ ar (L) & $-7,1464$ & 4,335649 & $-1,64830$ & 0,160207 & $-3,5732$ & 2,167824 \\
Q ar (Q) & $-14,4849$ & 5,161119 & $-2,80654$ & 0,037702 & $-7,2424$ & 2,580560 \\
(2) [ ] Amon(L) & 6,6733 & 4,335649 & 1,53916 & 0,184386 & 3,3366 & 2,167824 \\
$\quad$ [ ] Amon(Q) & $-27,8818$ & 5,161119 & $-5,40228$ & 0,002937 & $-13,9409$ & 2,580560 \\
1L by 2L & 0,4179 & 6,131071 & 0,06817 & 0,948296 & 0,2090 & 3,065535 \\
\hline
\end{tabular}

Notas: $\mathrm{R}^{2}=87,77 \%$; (L) - linear; (Q) - quadrático.

Observa-se, pelas linhas descartadas na Tabela 3, que a diminuição da concentração de amônia aumenta a formação de nitrato e que a diminuição da vazão de ar também influenciou significativamente na formação de nitrato.

A influência da amônia já era esperada, devido ao fato de ser a mesma biota em todos os ensaios; assim, quanto menos amônia se coloca à disposição desses microrganismos, mais rápido os mesmos deverão consumir esse nutriente e, consequentemente, convertê-lo a nitrato.

A diminuição da vazão de ar ocasionou o aumento da eficiência da nitrificação, o que não era esperado de forma significativa. Segundo FERREIRA (2000), valores de oxigênio na ordem de $4 \mathrm{mg} \mathrm{L}^{-1}$ são ideais para o processo de nitrificação e somente valores abaixo de $2,5 \mathrm{mg} \mathrm{L}^{-1}$ interfeririam no processo, de acordo com SURAMPALLI et al. (1997). Foi observada tendência em que os valores mais baixos testados aumentaram a eficiência da nitrificação, levando em consideração que os valores de OD neste experimento variaram, em média, entre $6,5 \mathrm{mg} \mathrm{L}^{-1}$ (com a menor vazão) e $8,5 \mathrm{mg} \mathrm{L}^{-1}$ (com a maior vazão), aproximadamente. Essa tendência se deve, provavelmente, à diminuição da eficiência da atividade microbiana ocasionada pelo desligamento dos microrganismos do meio-suporte, devido à maior turbulência no meio líquido observada no reator quando em maiores concentrações de oxigenação. Segundo HAGOPIAN \& RILEY (1998), a imobilização da biomassa favorece a eficiência do processo, pois possibilita situações que permitem melhor desempenho dos microrganismos. 
Ainda com essa visível tendência, não é possível afirmar que essa pequena diferença de concentração de oxigênio $\left(6,5\right.$ e $\left.8,5 \mathrm{mg} \mathrm{L}^{-1}\right)$ é suficiente para ser avaliada sua influência em maior escala ou de fato em outros ambientes controlados. Apenas é possível estimar, ainda que empiricamente, que valores ainda mais baixos de concentração de oxigênio podem ser mais influentes positivamente nessa etapa da nitrificação.

TABELA 41. Tabela de efeitos para a variável resposta acúmulo de nitrito. Effects of the response: accumulation of nitrite.

\begin{tabular}{lrrrrrc}
\hline & Efeito & $\begin{array}{c}\text { Erro-Padrão } \\
\text { do Efeito }\end{array}$ & $\begin{array}{c}\text { t de Student } \\
(5 \%)\end{array}$ & p-valor & $\begin{array}{c}\text { Coeficiente do } \\
\text { Modelo }\end{array}$ & $\begin{array}{c}\text { Erro do } \\
\text { Coeficiente }\end{array}$ \\
\hline Média & 16,20082 & 3,209153 & 5,04832 & 0,003939 & 16,20082 & 3,209153 \\
$(1) \mathrm{Q} \operatorname{ar}(\mathrm{L})$ & $-2,61482$ & 3,930690 & $-0,66523$ & 0,535354 & $-1,30741$ & 1,965345 \\
Q $\operatorname{ar}(\mathrm{Q})$ & $-6,23883$ & 4,679059 & $-1,33335$ & 0,239934 & $-3,11941$ & 2,339530 \\
(2)[ ] Amon(L) & 14,76070 & 3,930690 & 3,75525 & 0,013222 & 7,38035 & 1,965345 \\
[ ] Amon(Q) & 2,11370 & 4,679059 & 0,45174 & 0,670380 & 1,05685 & 2,339530 \\
1L by 2L & $-0,98684$ & 5,558415 & $-0,17754$ & 0,866052 & $-0,49342$ & 2,779208 \\
\hline
\end{tabular}

Nota: $\mathrm{R}^{2}=77,4 \%$; (L) - linear; (Q) - quadrático.

O aumento da concentração de amônia aumentou o acúmulo de nitrito e a vazão de ar não influenciou significativamente na formação de nitrito, no intervalo de confiança de $95 \%$. Foi observado que o acúmulo do nitrito esteve diretamente relacionado com a concentração de nitrato. Quando foi aumentada a concentração de nitrogênio amoniacal, houve aumento da conversão a nitrito e desse a nitrato.

O nitrato, segundo pesquisas de HUNIK et al. (1993), inibe a atividade das Nitrobacter agilis, que são bactérias nitratadoras. Sendo assim, a inibição dessas bactérias nitratadoras provoca acúmulo do nitrito, que é seu próprio substrato. Ainda segundo os mesmos autores, essa inibição pode ser inconveniente no tratamento de efluentes concentrados, pois não há como evitar o acúmulo do nitrato na nitrificação, quando separada da desnitrificação. Além da inibição do próprio substrato, outros fatores podem induzir o acúmulo de nitrito, tais como: baixo $\mathrm{pH}$, baixa concentração de oxigênio dissolvido, baixa temperatura e aumento da carga volumétrica (PHILIPS \& VERSTRAETE, 2001). Porém, neste experimento, todas essas variáveis que poderiam provocar a inibição foram monitoradas em todas as bateladas e mantiveram comportamento semelhante entre si, com mudanças nas concentrações observadas, porém sem indício de interferência nos ensaios realizados.

Nas Figuras 1 e 2, apresentam-se as superfícies de resposta geradas a partir dos dados da Tabela 2.

De acordo com a Figura 1, entre os fatores analisados, a faixa de combinação que permite melhor conversão do nitrogênio amoniacal a nitrato fica entre os pontos $-0,2$ e 0,5 , que representam os valores de 65 e $81 \mathrm{mg} \mathrm{L}^{-1}$ de nitrogênio amoniacal, e entre os pontos $-0,6$ e 0,2 , que representam os valores estimados de 1,5 e $2,1 \mathrm{~L} \mathrm{~min}^{-1}$ de vazão de ar. Contudo o ponto testado com maior eficiência de nitrificação foi o de combinação vazão de ar de $2 \mathrm{~L} \mathrm{~min}^{-1}$ e concentração de nitrogênio amoniacal de $70 \mathrm{mg} \mathrm{L}^{-1}$. Nesse ponto, obteve-se eficiência de $86 \%$ de conversão a nitrato, visto que o consumo do nitrogênio amoniacal foi total (100\%). Abaixo dessa faixa de concentração de nitrogênio amoniacal, a conversão não foi maior, provavelmente, devido à utilização do nitrogênio pelas bactérias, na manutenção da vida celular. O nitrogênio amoniacal é assimilado também em processos metabólicos na síntese celular (BROCK \& MADIGAN, 1994; VIEIRA et al., 1991). 


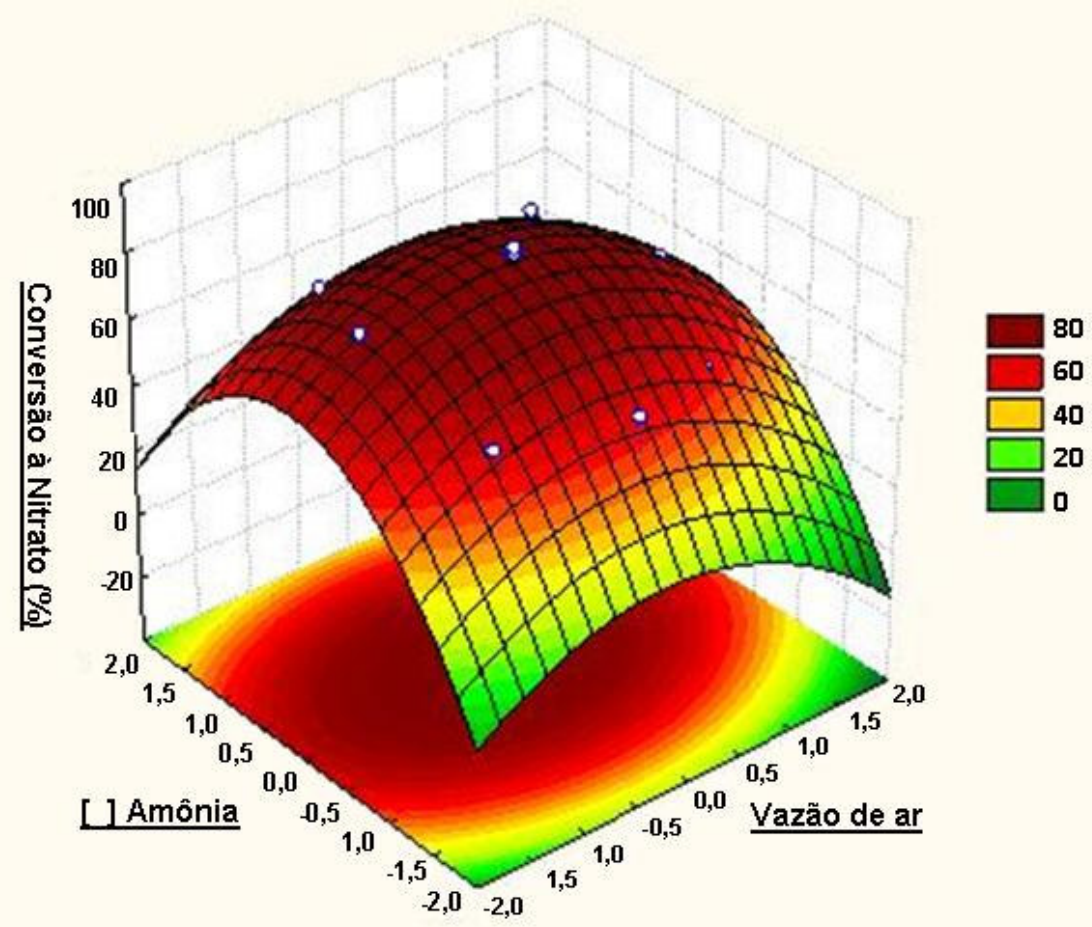

FIGURA 1. Superfície de resposta para a variável conversão a nitrato. Surface response for the nitrate variable conversion.

Acima dos valores médios testados de nitrogênio amoniacal (70 a $80 \mathrm{mg} \mathrm{L}^{-1}$ ), observou-se, além da diminuição na conversão a nitrato, o aumento no acúmulo de nitrito, conforme Figura 2.

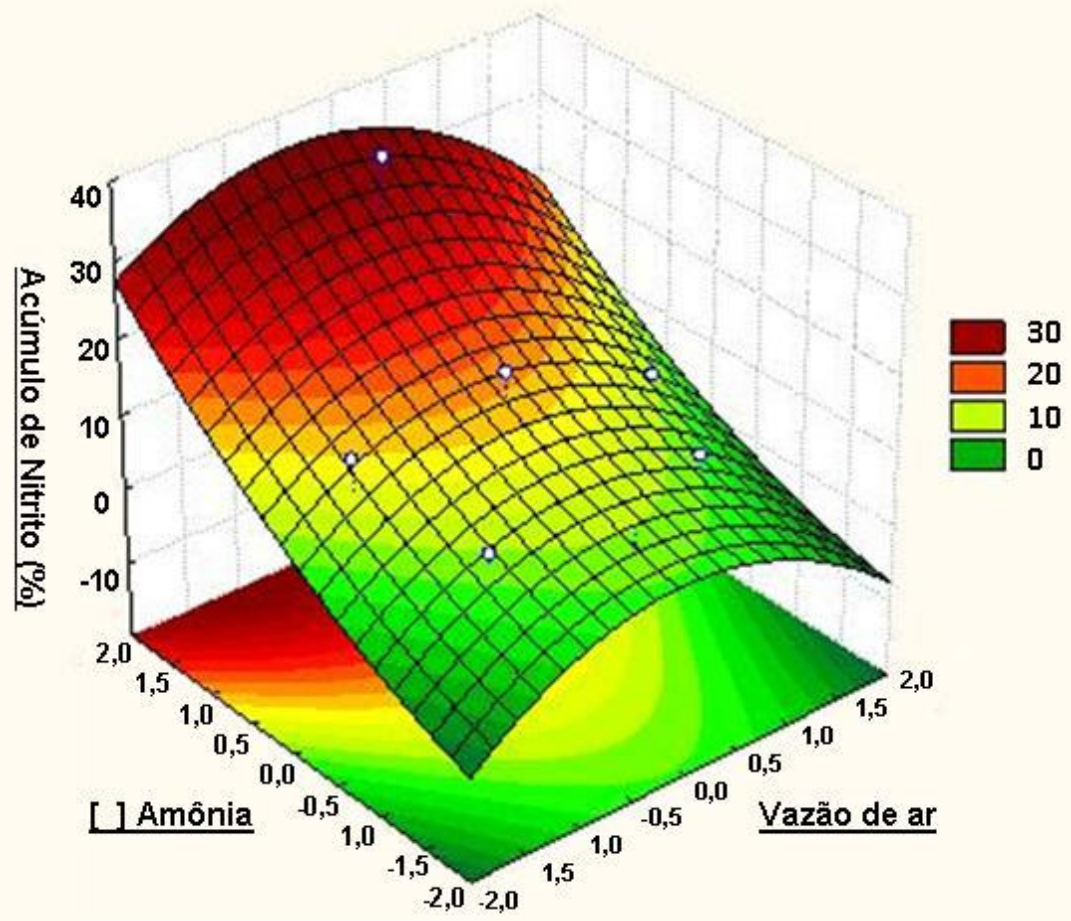

FIGURA 2. Superfície de resposta para a variável acúmulo de nitrito. Surface response for the nitrite accumulation variable.

Na Figura 2, apresenta-se a tendência observada nos testes realizados, na qual o início de acúmulo de nitrito, com $95 \%$ de confiança, deu-se somente com o aumento da concentração de 
nitrogênio amoniacal. A partir da análise das condições controladas, supõe-se que o acúmulo de nitrito observado pode ter ocorrido devido à inibição das Nitrobacter por seu próprio substrato.

A eficiência de nitrificação observada por ISOLDI et al. (2003), em reator aeróbio para tratamento de água residuária de industrialização de arroz, foi de 55\% de conversão a nitrato, com consumo de nitrogênio amoniacal de 75\%. ZENATTI (2007) testou um reator aeróbio no tratamento de efluente de abatedouro de peixes obtendo conversão, em seu experimento, de 57\%, com consumo de nitrogênio amoniacal de $85 \%$, enquanto testava tempos de detenção hidráulica de, no máximo, 12 horas. $\mathrm{O}$ fato de a eficiência neste trabalho ter sido maior, pode ser devido ao aumento do tempo em relação ao experimento de ZENATTI (2007) e também à concentração de oxigênio dissolvido ser maior do que no experimento de ISOLDI et al. (2003).

No reator biológico aerado utilizado por PEREIRA-RAMIREZ et al. (2003), foi utilizado TDH de 20 horas em reator com recirculação de lodo, período em que foram alcançados $90 \%$ de nitrificação. Provavelmente, a maior eficiência obtida pelos autores seja devida à recirculação de lodo e ao controle da idade do lodo, que variou de 20 a 23 dias.

\section{CONCLUSÕES}

De acordo com os experimentos realizados, pode-se concluir que o reator se mostrou eficiente para a nitrificação de efluente de abatedouro de peixes. Os fatores em teste influenciaram significativamente com intervalo de confiança de $95 \%$ no processo de nitrificação.

A eficiência na conversão de nitrogênio amoniacal a nitrato aumentou de forma significativa com a diminuição das concentrações de nitrogênio amoniacal e de vazão de ar para as concentrações testadas.

A percentagem de conversão a nitrato apresentou valores extremos de 53,4 e $86 \%$, e os melhores valores de conversão (com média de 85\%) foram obtidos quando em condições de concentração de nitrogênio amoniacal de $70 \mathrm{mg} \mathrm{L}^{-1}$ e com vazão de ar de $2 \mathrm{~L} \mathrm{~min}^{-1}$.

A percentagem de acúmulo de nitrito variou entre 5 e 35,7\%, sendo influenciada pela concentração de amônia, de forma que o aumento dessa provocou a acumulação de nitrito, efeito não observado para a vazão de ar.

Os fatores $\mathrm{pH}$, relação $\mathrm{C} / \mathrm{N}$ e alcalinidade, que foram monitorados em todas as bateladas, mantiveram comportamento semelhante entre si, não havendo indício de interferência sobre os resultados obtidos neste estudo.

\section{REFERÊNCIAS}

ABREU, L.M. Aspectos microbiológicos de los procesos de nitrificación-desnitrificación. In: TALLER Y SEMINARIO LATINO AMERICANO TRATAMIENTO DE AGUAS RESIDUALES, 3., 1994, Montevideo. Anais... Montevideo: Universidad de la Republica, 1994. p. 55-63.

APHA. AMERICAN PUBLIC HEALTH ASSOCIATION; AWWA. AMERICAN WATER WORKS ASSOCIATION; WPCF. WATER ENVIRONMENT FEDERATION. Standard methods for the examination of water and wastewater. $20^{\text {th }}$ ed. Washington: American Public Health Association, 1998.

BARROS NETO, B.; SCARMINIO, I.S.; BRUNS, R.E. Planejamento e otimização de experimentos. 2.ed. Campinas: Editora da UNICAMP, 1996. 299 p.

BRASIL. Ministério do Meio Ambiente. CONAMA. Resolução no 357, de 17 de março de 2005. Dispõe sobre a classificação dos corpos de águia e diretrizes ambientais para o seu enquadramento, bem como estabelece as condições e padrões de lançamento de efluentes, e dá outras providências. Publicado no Diário Oficial da União em 18-3-2005. Seção 1, p.58 a 63. 
BRASIL. Secretaria Especial de Aquicultura e Pesca - SEAP. Aquicultura no Brasil. Disponível em: http://www.presidencia.gov.br/estrutura_presidencia/seap/aqui/ Acesso em: 14 jun. 2007.

BROCK, T.D.; MADIGAN, M.T. Biology of microrganisms. New Jersey: Prentice Hall, 1994. $909 \mathrm{p}$.

FERREIRA, E. Cinética química e fundamentos dos processos de nitrificação e desnitrificação biológica. In: CONGRESSO INTERAMERICANO DE ENGENHARIA SANITÁRIA E AMBIENTAL, 27., 2000, Porto Alegre. Anais... Rio de Janeiro: ABES, 2000. 1 CD-ROM.

HAGOPIAN, D.S.; RILEY, J.G. A closer look at the bacteriology of nitrification. Aquacultural Engineering, Kidlington, v.18, n.4, p.223-244, 1998.

HUNIK, J.H.; MEIJER, H.J.G.; TRAMPER, J. Kinetics of nitrobacter agilis at extreme substrate, product and salt concentrations. Applied and Microbiology Biotechnology, Heidelberg, v.40, n.2-3, p.442-448, 1993.

ISOLDI, L.A.; KOETZ, P.R. Tratamentos biológicos para remoção de matéria carbonada e nitrogenada. Revista Eletrônica do Mestrado em Educação Ambiental, Rio Grande, v.12, n.1, p.1$12,2004$.

ISOLDI, L.A.; KOETZ, P.R.; FARIA, O.L.V.; ISOLDI, L.A. Remoção de carbono orgânico e nitrificação de águas residuárias da industrialização de arroz. Revista Brasileira Agrociência, Pelotas, v.9, n.3, p.273-277, 2003.

KAWANO, M.; HANDA, R.M. Filtros biológicos e biodisco. Revista Bolsa de Reciclagem, São Paulo. Disponível em: www.bolsafiesp.com.br. Acesso em: 10 dez. 2002.

PEREIRA-RAMIREZ, O.; ANTUNES, R.M.; QUADRO, M.S.; KOETZ, P. R. Remoção da DQO e nitrificação em reator biológico aerado no pós-tratamento de águas residuárias de suinocultura. Revista Brasileira Agrociência, Pelotas, v.9, n.3, p.279-286, 2003.

PHILIPS, S.; VERSTRAETE, W. Effect of repeated addition of nitrite to semi-continuous activated sludge reactors. Bioresource Technology, Gent, v.80, n.1. p.73-82, 2001.

PINHEIRO, R. Empreendedores investem na Tilápia. Rev. Sindicato das Indústrias da Pesca de Itajaí e Região - SC (SINDIPI). 19. ed. Itajaí: Alpha Comunicação, 2006. 65 p.

SURAMPALLI, R.Y.; TYAGI, R.D.; SCHEIBLE, O.K.; HEIDMAN, J.A. Nitrification, denitrification and phosphorus removal in sequential batch reactors. Bioresource Technology, Oxford, v.61, n.2, p.151-157, 1997.

TORRES, S.; ASPÉ, E.; MATI, M. C. Differential bacterial growth kinetic and nitrification of fisheries wastewaters containing high ammonium and organic matter concentration by using pure oxygen. Biotechnology Letters, Netherlands, v.19, n.3. p.241-244, 1997.

VADIVELU, V.M.; KELLER, J.; YUAN, Z. Effect of free ammonia on the respiration and growth processes of an enriched Nitrobacter culture. Water Research, Oxford, v.41, n.4, p.826-834, 2007.

VIEIRA, E.C.; GAZZINELLI, G.; MARES-GUIA, M. Bioquímica celular e biologia molecular. 2. ed. São Paulo: Atheneu, 1991. 306 p.

ZENATTI, D.C. Avaliação da nitrificação de efluente de abatedouro de tilápia em reator em batelada sequencial com biomassa imobilizada. 2007. 90 f. Dissertação (Mestrado em Recursos Hídricos e Saneamento Ambiental) - Universidade Estadual do Oeste do Paraná, Cascavel, 2007. 